\title{
Modified gelatine structures as packaging material for frozen agricultural products
}

\author{
Katarzyna Kozłowicz ${ }^{*}$, Franciszek Kluza ${ }^{1}$, Dariusz Góral $^{1}$, Piotr Nakonieczny ${ }^{1}$, and Maciej Combrzyński ${ }^{2}$ \\ ${ }^{1}$ University of Life Sciences in Lublin, Department of Refrigeration and Food Industry Energetics, ul. Doświadczalna 44, \\ 20-280 Lublin, Poland \\ ${ }^{2}$ University of Life Sciences in Lublin, Department of Process Engineering, ul. Doświadczalna 44, 20-280 Lublin, Poland
}

\begin{abstract}
Gelatine gels modified by hydrated paper pulp (PP), ground extruded starch (ES) and hydrogel balls (HGB) were formed so that after the crosslinking process, the plates of suitable thickness could be obtained. Then the material was freeze-dried and the obtained porous gelatine structures as well as styrofoam (XPS) as the reference material were tested for thermal conductivity and bending. The temperature fields were examined during the thawing process of products placed inside the test packagings with modified gelatine structures and polystyrene as well as temperature field profile on outer surface of these packs. The studied materials resemble styrofoam in terms of thermal insulation and exhibited medium thermal conductivity ranging between 0.047 and 0.081 $\left[\mathrm{W} \cdot(\mathrm{mK})^{-1}\right]$. The bending strength of the materials under investigation proved higher than that of styrofoam and this fact supports their applicability as an alternative for frozen agricultural products packages.
\end{abstract}

\section{Introduction}

The primary function of packaging material is to maintain freshness and quality of raw materials and agricultural products, especially those chilled and frozen. Packaging needs to possess suitable barrier properties, a degree of thermal insulation and mechanical strength. The material for food packaging should meet a number of essential technical and legislative regulations [1-2]. It is also expected to be biodegradable, namely, the most eco-friendly possible. Biodegradable packaging material can be produced from animal-derived substances (collagen, gelatine, casein, albumin, etc) or plant-based (cellulose and its derivatives, starch). The choice of suitable packaging material and its form also relies on the factors associated directly with the physicochemical characteristics of packed products, i.e. chemical state, texture, porosity as well as the time and storage conditions [3]. In response to increased awareness of consumers and high demand for quality, new packaging materials have been introduced [4-8].

The objective of the study was working out, development and characterization of the basic thermophysical properties of the material based on modified gelatine gels intended for frozen products packaging.

\section{Materials and methods}

The research material included lyophilized solidified and modified gelatine gels. The processes used to produce them involved crosslinking, swelling, freezing and sublimation drying. To obtain 5\% gelatine solution, demineralized water and gelatine type A (Gellwe, Poland) were employed. The chilled sol (5\% gelatine) modified by hydrated paper pulp (PP), ground extruded starch (ES) and hydrogel balls (HGB) was casted into cuboid-shaped molds and allowed to remain for 12 hours at the ambient temperature to promote the crosslinking reaction. The appropriate dose rates of the modified sol were to ensure, after the crosslinking process, production of the plates of the same $9 \mathrm{~mm}$ thickness. The solidified gel samples were frozen in a chest freezer at natural convection at $-33^{\circ} \mathrm{C}$ temperature. Gel sublimation drying was performed in the Alpha 2-4LD Plus freeze-dryer (Martin Christ Freeze Dryers, Germany) at the constant pressure $20 \mathrm{~Pa}$ in the chamber, ice condenser chamber temperature $-64^{\circ} \mathrm{C}$, drying chamber temperature $-36^{\circ} \mathrm{C}$ and drying time of 72 hours.

The obtained material in the form of porous gelatine structures and styrofoam (XPS) as the reference material were analyzed for thermal conductivity (KD2 Pro thermal properties analyzer with KS-1 probe Decagon Devices, USA) and subjected to strength tests (texture analyzer LFRA 4500; Brookfield, USA) using the three point bend test (a symmetrical knife of 30-degree blade angle, blade thickness $3 \mathrm{~mm}$, shift velocity $0.5\left[\mathrm{~mm} \cdot \mathrm{s}^{-1}\right]$, sampling time 100 measurements per sec, measurement accuracy $\pm 0.01 \mathrm{~N}$ ) [9]. Sample density was calculated as the ratio of sample mass to their volume. The mean from 5 replications was assumed as the final result. The obtained porous structures in a form of plates served to

Corresponding author: katarzyna.kozlowicz@up.lublin.pl 
produce packaging for frozen products. To make comparative assessment of the packaging usability, temperature fields recorded at the thawing process of the products placed inside them were studied. The thawing operation was ceased when the product surface temperature reached $18^{\circ} \mathrm{C}$. The temperature was measured and recorded by temperature analyzer LB515P (LAB-EL, Poland) coupled with button data loggers for temperature and humidity (type 23). The loggers recorded the surface temperature of a frozen product (carrot) inside the test packs. The measurements were carried out for 22 hours. The obtained data made basis for thawing kinetics analysis. The temperature field profile on the test pack surface during the thawing process was evaluated with TESTO 882 infrared camera (Testo, UK). The assessment of temperature distribution was made using the TestoIRSoft software ver. 3.4 assisting the thermal imaging camera.

The research results were analyzed using the Statistica 13 kit and Microsoft Excel program.

\section{Results and discussion}

Thermal conductivity is a key property of insulating materials. Its interpretation, however, imposes the "converse logic", namely, the lower the thermal conductivity coefficient, the better its thermal insulating properties. The value of this characteristic depicting given material depends on several parameters and factors but predominantly on material composition and temperature [10]. The measured thermal conductivity values of the modified and lyophilized materials and the reference material - styrofoam were tabulated (Table 1). The thermal conductivity of gelatine structures was found within the $0.047-0.081\left[\mathrm{~W} \cdot(\mathrm{mK})^{-1}\right]$ range. The mean thermal conductivity of styrofoam averaged 0.033 $\left[\mathrm{W} \cdot(\mathrm{mK})^{-1}\right]$. As regards thermal insulation, the obtained gelatine structures, just like styrofoam, can be applied as packaging material for frozen products.

Table 1. Physical properties (mean \pm standard deviation) of styrofoam and freeze-dried samples.

\begin{tabular}{|c|c|c|c|}
\hline Sample & $\begin{array}{c}\text { Thermal } \\
\text { conductivity } \\
{\left[\mathbf{W} \cdot(\mathbf{m K})^{-1}\right]}\end{array}$ & $\begin{array}{c}\text { Bending force } \\
{[\mathbf{N}]}\end{array}$ & $\begin{array}{c}\text { Density } \\
{\left[\mathbf{k g}^{-3} \mathbf{m}^{-3}\right]}\end{array}$ \\
\hline XPS & $0.033 \pm 0.002^{\mathrm{a}}$ & $3.35 \pm 0.17^{\mathrm{a}}$ & $36.37 \pm 1.15^{\mathrm{a}}$ \\
\hline PP & $0.081 \pm 0.008^{\mathrm{b}}$ & $11.86 \pm 0.27^{\mathrm{b}}$ & $90.33 \pm 9.07^{\mathrm{b}}$ \\
\hline ES & $0.054 \pm 0.004^{\mathrm{c}}$ & $4.74 \pm 0.41^{\mathrm{c}}$ & $159.0 \pm 7.94^{\mathrm{c}}$ \\
\hline HGB & $0.047 \pm 0.003^{\mathrm{d}}$ & $4.17 \pm 0.28^{\mathrm{d}}$ & $66.33 \pm 13.20^{\mathrm{a}}$ \\
\hline
\end{tabular}

Apart from low thermal conductivity, packaging material must have good mechanical strength. The bend testing has indicated considerably higher mechanical strength of the new material as compared to the styrofoam sample (Table 1). The mean maximum damage parameter established for gelatine material modified by paper mass was $11.86 \mathrm{~N}$, while $4.74 \mathrm{~N}$ in case of modification by extruded starch and $4.17 \mathrm{~N}$ by hydrogel balls. The lowest damage parameter had the styrofoam sample $(3.35 \mathrm{~N})$. Notably, higher force required to damage the sample proves that in this context, gelatine material can be considered a better raw material for packaging production than styrofoam. Hence, it is possible to manufacture packaging of markedly higher strength with, importantly, a similar thermal insulation parameter.

Density is a main parameter in material characteristics as it provides information on the mass per unit volume [11]. The lowest density was recorded for the gelatine structures modified by hydrogel balls ( 66.33 $\left.\left[\mathrm{kg} \cdot \mathrm{m}^{-3}\right]\right)$, whereas the highest for those modified by extruded starch $\left(159.0\left[\mathrm{~kg} \cdot \mathrm{m}^{-3}\right]\right)$. Yet, the obtained density values were higher than those characterizing the reference material- styrofoam $\left(36.37\left[\mathrm{~kg} \cdot \mathrm{m}^{-3}\right]\right)$.

The thawing curve constitutes the major source of the data for determination of the sample temperature at the thawing process [12]. Taking into account the thawing curves established (Fig.1), it was found that the temperature in the styrofoam packaging was below $0^{\circ} \mathrm{C}$ and it maintained for the longest time, namely over 15.5 $\mathrm{h}$. The temperature of $0^{\circ} \mathrm{C}$ was recorded in the packaging obtained from gelatine structures after $10 \mathrm{~h}$ (modified by paper pulp) and $8 \mathrm{~h}$ (modified by extruded starch and hydrogel balls).

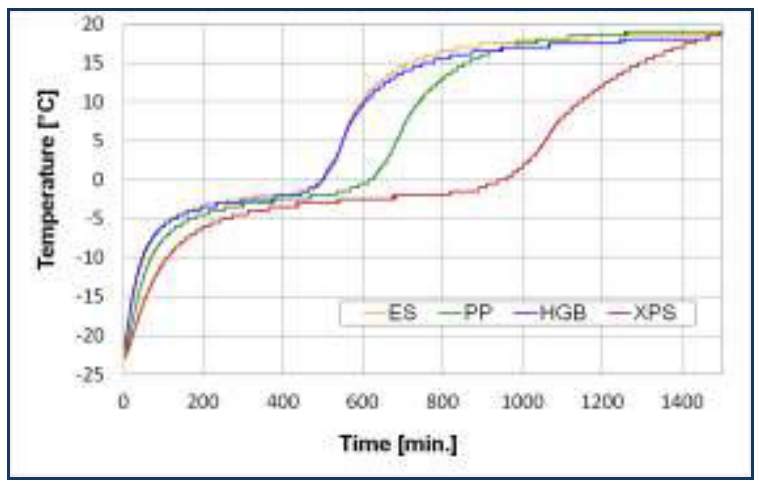

Fig. 1. Thawing curves of frozen product placed in test packs.

The changes in the temperature on the outer surface of test packs with a deep-frozen product were recorded by an infrared camera. Figure 2 presents the infrared image of the surface of packagings made from the studied materials together with analysis of the temperature profile and its extreme values. The point CS1 denotes the minimum temperature, while HS1 - the maximum one. The lowest surface temperature at the CS1 point was established for the packaging obtained from the hydrogel balls-modified material $\left(8.2^{\circ} \mathrm{C}\right)$ and the material modified by paper pulp $\left(12.9^{\circ} \mathrm{C}\right)$. As for the styrofoam packaging, the minimum surface temperature was $19.5^{\circ} \mathrm{C}$. Considering the point $\mathrm{HS} 1$, the lowest maximum was determined for the packaging manufactured from the gelatine structure modified by paper pulp $\left(22.1^{\circ} \mathrm{C}\right)$, whereas the highest for that extruded starch-modified $\left(23.3^{\circ} \mathrm{C}\right)$. The presented temperature distribution profiles showed that the product got frozen (stuck) periodically to the surface of its packaging from the material based on the hydrogel ballsmodified gelatine structure. 
a.

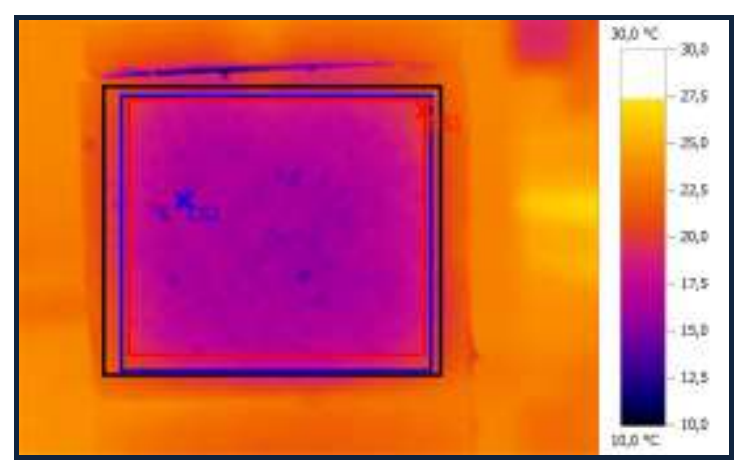

b.

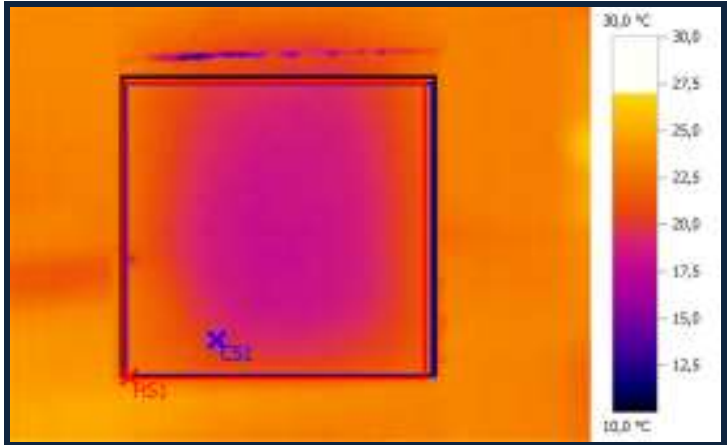

c.

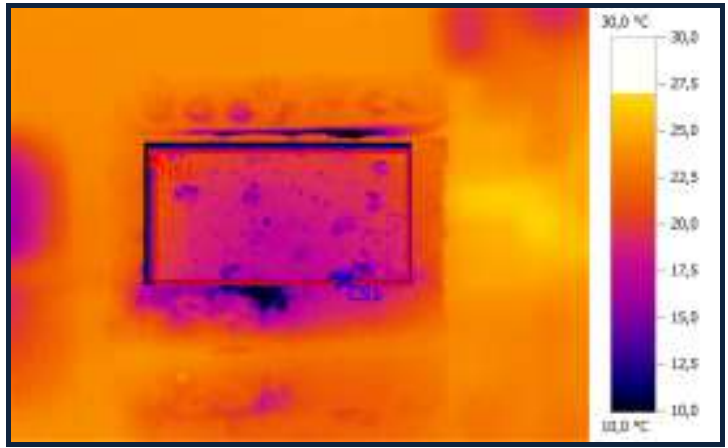

d.

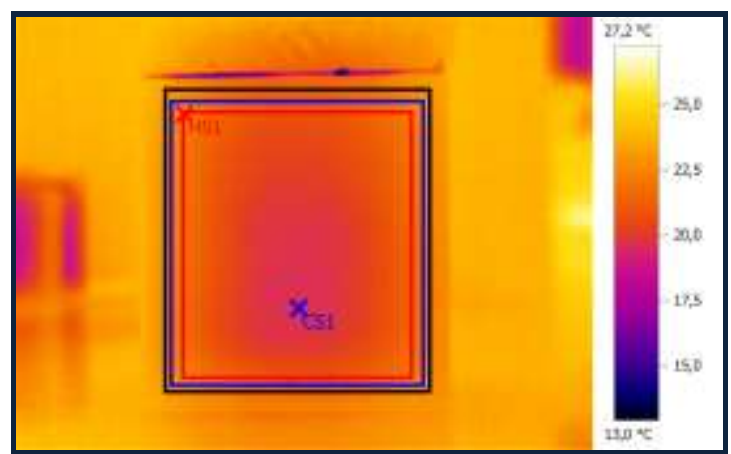

Fig. 2. Infrared image of packaging surface with analysis of temperature profile and its extreme values, a. PP, b. ES, c. HGB, d. XPS

The temperature distribution profiles were analyzed together with the histograms created (Fig. 3). A histogram is a graphical representation of the empirical distribution of characteristics which means that it serves to present the results obtained for some quantitative variables. The histogram for the packaging surface area shows a percentage share of each temperature value denoted as colour pixels on the infrared image.
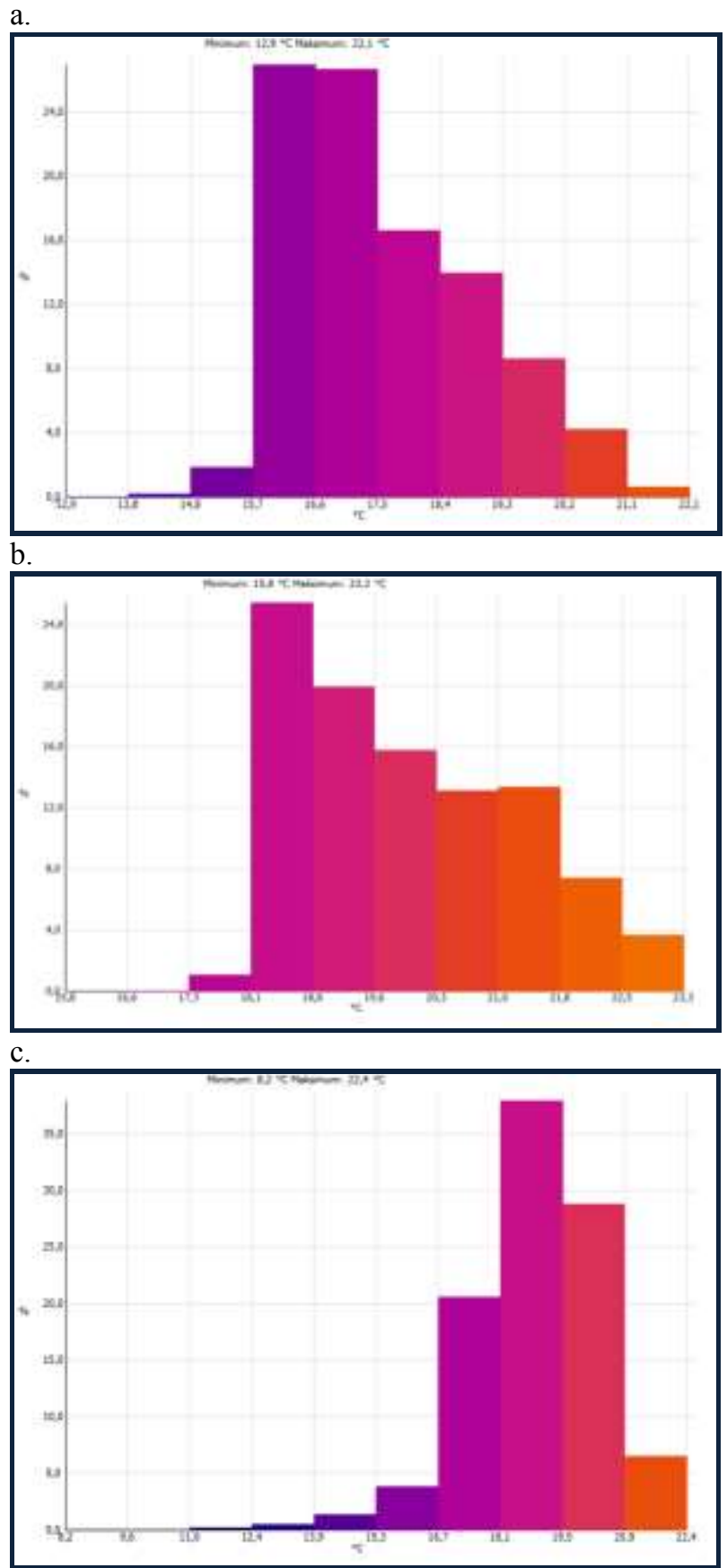

d.

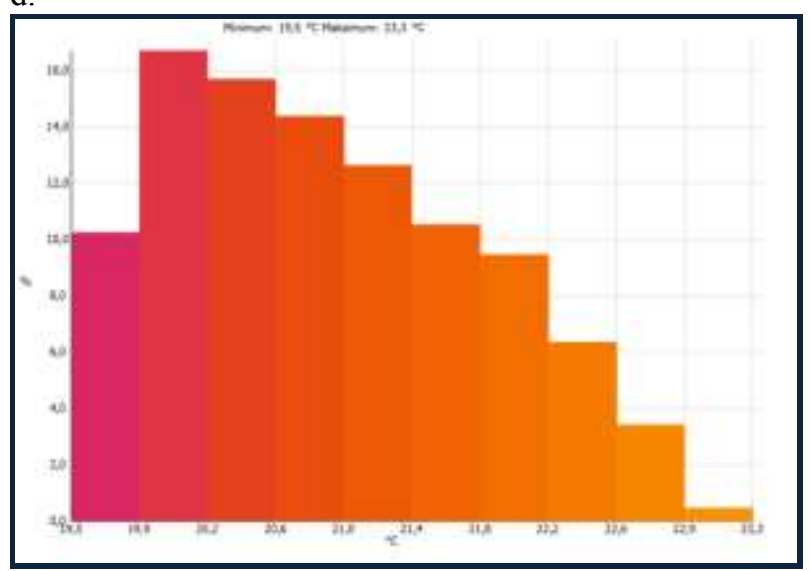


Fig. 3. The histogram of temperature distribution on pack surface: a. PP, b. ES, c. HGB, d. XPS

The highest percentage rate in the entire area for the packaging made of the material modified by paper pulp was determined for the temperatures ranging between approximately 15.7 and $16.6^{\circ} \mathrm{C}$, that accounts for circa $27 \%$ of the total percentage of the temperatures. As regards the packaging based on extruded starch-modified material, it was determined for the temperatures varying from 18.1 to $18.8^{\circ} \mathrm{C}$, which constitutes about $25 \%$. The histogram created for the styrofoam packaging displays that the highest percentage share in the entire area had the temperatures from the 19.9 up to $20.2^{\circ} \mathrm{C}$ range, that is circa $16 \%$ of total percentage of the temperatures.

The research results are consistent with those reported in the earlier studies by Kozłowicz and others [13] who used lyophilized gelatine structures as packaging material for frozen foods with good properties of thermal insulation. The mean thermal conductivity of these structures was $0.054\left[\mathrm{~W} \cdot(\mathrm{mK})^{-1}\right]$ and density 71.16 $\left[\mathrm{kg} \cdot \mathrm{m}^{-3}\right]$. Besides, gelatine as a natural-origin polymer is commonly used as a drug delivery carrier, dressing material and tissue engineering scaffolds [14]. The production ease, low density and porosity of lyophilized gelatine structures as well as feasible complete biodegradability of such insulating material make it an efficient replacer of polystyrene in the packaging manufacture process. It is also worth noting that recently many packaging manufacturers have applied natural raw materials more frequently. These are polysaccharides (corn and potato starch, cellulose, gums), animal proteins (casein, collagen, gelatine), plant-based (soybeans, gluten) and lipids (fats oils) [6, 15-17] that allow maintaining a suitable quality of the packaged raw materials.

\section{Conclusion}

The obtained material that varied in composition displayed the thermal insulation properties similar to these of the reference material - styrofoam. Therefore, the lyophilized gelatine structures are applicable for packaging of agricultural frozen foods. Their mean thermal conductivity ranged from 0.047 up to 0.081 $\left[\mathrm{W} \cdot(\mathrm{mK})^{-1}\right]$, whereas for the styrofoam tested, it averaged $0.033\left[\mathrm{~W} \cdot(\mathrm{mK})^{-1}\right]$. As for packaging material based on lyophilized gels with hydrogel balls and paper mass, frost penetration was observed at only some sites. The investigations have confirmed that the proposed materials made from lyophilized porous gelatine gels with paper mass, hydrogel balls or starch can constitute an alternative to the materials employed presently as packaging for agricultural frozen products. By reason of gelatine properties (a natural polymer), the obtained gelatine structures are fully biodegradable and easily compostable.

\section{References}

1. G. Robertson, Food packaging: principles and practice, CRC Press, Boca Raton (2013)

2. Regulation (EC) No 1935/2004 of the European Parliament and of the council on materials and articles intended to come into contact with food and repealing Directives 80/590/EEC and 89/109/EEC

3. B. Grabowska, Przem. Spoż. 68, 9, 16-18 (2014), (in Polish)

4. S. Farris, K.M. Schaich, L. Liu, L. Piergiovanni, K.L. Yam, Trends Food Sci. Technol. 20, 316-332 (2009)

5. P.A. Pawar, A.H. Purwar, AJER 02, 05, 151-164 (2013)

6. A. Rejak, A. Wójtowicz, T. Oniszczuk, Przem. Chem. 92, 11, (2013)

7. V. Siracusa, P. Rocculi, S. Romani, M. Rosa, Trends Food Sci. Technol. 19, 634-643 (2008)

8. C.J. Weber, V. Haugaard, R. Festersen, G. Bertelsen, Food Additives \& Contaminants, 19(S1), 172-177 (2002)

9. B.M. McKenna, Texture in food, CRC Press, Boca Raton (2003)

10. Da-Wen Sun, Handbook of frozen food processing and packaging, CRC Press, Boca Raton (2006)

11.P.A. Webb, Volume and density determinations for particle technologists. Micromeritics Instruments Corp., www.micromeritics.com

12. IIR. Recommendations for the processing and handling of frozen foods, Int. Institute of Refrigeration, Denmark (2006)

13. K. Kozłowicz, D. Góral, F. Kluza, M. Domin, Z. Kobus, A. Sagan, Ł. Prazner, Przem. Chem., 94, 10 1742-1747 (2015)

14. A.A. Karim, R. Bhat, Trends Food Sci. Technol. 19, 644-656 (2008)

15. H.W. Kang, Y. Tabata, Y. Ikada, Biomaterials, 20, 14, 1339 (1999)

16. X. Wu, Y. Liu, X. Li, P. Wen, Y. Zhang, Y. Long, X. Wang, Y. Guo, F. Xing, J. Gao, Acta Biomater. 6, 3, 1167 (2010)

17. H. Kim, J. Knowles, H.H. Kim, J. Biomed. Mater. Res. 72, 136 (2005) 